\title{
ACCEPTANCE OF COVID-19 VACCINES AMONG NURSES
}

\author{
By \\ Elmetwaly MMF${ }^{1}$, Fahmy $\mathrm{MM}^{3}$, El-Gilany $\mathrm{A}^{1}$, Bauomy $\mathrm{ES}^{2}$ and Taref $\mathrm{NN}^{2}$ \\ ${ }^{1}$ Department of Public Health and Community Medicine, Faculty of Medicine, ${ }^{2}$ Department of \\ Community Health Nursing, Faculty of Nursing, Mansoura University, Egypt and \\ ${ }^{3}$ Department of Pediatric, Mansoura Specialized Hospital.
}

Corresponding Author: Elmetwaly MMF. E mail:m_fahmi@mans.edu.eg

DOI: $10.21608 /$ ejom.2021.97788.1252

Submit Date: 2021-09-28

Revise Date: 2021-10-18

Accept Date: $2021-10-23$

Authors' contribution: El-Gilany A: The idea of the research, Fahmy MM: Questionnaire design, Elmetwaly MMF, Fahmy MM and El-Gilany A: statistical analysis and editing,

Bauomy ES and Taref NN: Data collection, Taref NN and Elmetwaly MMF: Data entry.

\begin{abstract}
Introduction: Nurses are among the most occupationally exposed groups to Corona Virus Disease -19 (COVID-19) infections and their protection is crucial. Currently, many types of vaccines are developed but there are still many issues related to their acceptance among different occupational groups. It is vital to investigate this issue for clarification of the problem and timely targeting of its roots, particularly among the highly exposed workers. Aim of Work: To estimate the level of vaccine acceptance among a group of nurses in Mansoura University Hospitals, Egypt, and to shed the light on vaccines acceptance associated factors, and the reasons for non-acceptance. Materials and Methods: This is an observational descriptive cross-sectional study that was conducted on 262 nurses working in Mansoura University Hospitals, Egypt, during the year 2021. Data were collected using an anonymous self-administered questionnaire. Vaccines' acceptance was questioned, and the reasons for not accepting the vaccines were ascertained. Results: Only $22.1 \%$ of nurses in Mansoura University Hospitals accepted to be vaccinated ( $4.2 \%$ already vaccinated and $17.9 \%$ are willing to take the vaccine) especially those with self-reported good health status [adjusted odds ratio $(\mathrm{AOR})=3.5(1.5-8.1)]$. The independent predictor on logistic regression is good/ fair self-rated health with $\mathrm{AOR}=3.5$ (1.5-8.1). Concerns about vaccines safety and side effects were the most reported reasons for non-acceptance of vaccination. Vaccine safety concerns and distrust issues were reported. Conclusion and Recommendations: Being a male, previously infected, with good or fair self-rated health were associated
\end{abstract}


with more vaccine acceptance .Nurses' education and increasing awareness are required to correct misinformation about different types of COVID-19 vaccines and improve acceptance of nurses to vaccination. This would be a crucial preventive strategy that targets a highly exposed occupational group. This can be accomplished via health education sessions and increasing workers' motivation towards vaccination.

Key words: Nurses, COVID-19, Vaccination, Acceptance, Vaccines' safety and Vaccines side effects.

\section{Introduction}

COVID-19 infection is a global health threat (Fisher et al., 2020). The pandemic is overwhelming the health system and draining a lot of resources (Nicola et al., 2020). Nurses are valuable human resources in health system, so their protection is a crucial issue, especially with their high vulnerability to infection (Phua et al., 2020). Nonspecific preventive measures against COVID-19 infection include adequate ventilation, hand washing with soap and water or disinfectants, and respiratory hygiene such as covering nose and mouth (McIntosh et al., 2020). COVID-19 vaccination provides protection not only to the vaccinated individuals, but also to the general population if sufficient proportion of the population was vaccinated $(\mathrm{Wu}$ et al., 2014). Many vaccine varieties with different mechanisms of actions are available as recombinant protein vaccines, RNA vaccines, and vectorbased vaccines. These vectors can be a virus or a non-pathogenic bacterium
(Wang et al., 2020). The area of COVID-19 vaccination is still new and lacking information, yet it is crucial in disease prevention. COVID-19 vaccine is freely available in Mansoura University Hospitals, and priority is given to all health care workers including nurses, despite of that, there is reluctance or some unacceptability to vaccination. Commonly reported reasons include lack of information about the vaccine and concerns about its side effects (Abdelhafiz et al., 2020).

\section{Aim of Work}

To estimate the level of vaccine acceptance among a group of nurses in Mansoura University Hospitals, Egypt, and to shed the light on vaccines acceptance associated factors, and the reasons for non-acceptance.

\section{Materials and Methods}

Study design: An observational descriptive cross-sectional study.

\section{Place and duration of the study:} The study was conducted on nurses 
working in Mansoura University Hospitals, Egypt during the first two months of 2021.

\section{Study sample and pilot study:} Sample size was calculated online using the Open epi program (https://www. openepi.com/SampleSize/). An internal pilot study on 50 nurses revealed that $20 \%$ of them accept to be vaccinated with COVID-19 vaccine. With 5\% alpha error and $5 \%$ precision, then the calculated sample size was 246 nurses. The total number of nurses on duty in Mansoura University Hospitals is 2415 (1898 with Nursing Bachelor and 517 with Nursing Technical Diploma). A systematic random sample of 301 was selected (each 8th) and 262 nurses responded (response rate was $87.0 \%$ ).

Study methods: An anonymous Arabic self-administered questionnaire was developed after extensive literature review to collect the following data (Fisher et al., 2020; Nzaji et al., 2020): 1. Sociodemographic data (age, sex, marital status, qualification, annual household income, and residence). 2. Work information (occupation, specialty, and years of experience). 3 . Knowledge about COVID-19 infection and expectations about the possibility of being infected, in addition to self-rated general health. 4. Whether vaccinated or not and willingness to be vaccinated against COVID-19 in addition to reasons for negative answers.

Inclusion criteria were willingness to participate in the study and being a nurse on duty for at least one year at the time of data collection. Operational definition of COVID-19 vaccine acceptance is either being already vaccinated or willing to get the vaccine.

\section{Consent}

An informed oral consent was obtained from each participant in the study after thorough explanation of the aim of the study and the benefits behind it to the nurses' community and after ensuring confidentiality. Participants were allowed to respond anonymously to the questionnaire and in their own time and privacy.

\section{Ethical Approval}

Study proposal was approved by the Institutional Research Board (IRB), Faculty of Medicine, Mansoura University. Proposal code is R.21.01.1144.R1.R2.

\section{Data Management}

Data were collected, entered, and cleaned. Analysis was performed using 
Statistical Package of Social Sciences associated with vaccine acceptance on (SPSS) software version 23 (SPSS Inc., bi-variate analysis were entered into Chicago, IL, United States of America). $\quad$ multivariate logistic regression models Categorical variables were presented as number and percent. Chi-square test was used for comparison between groups. Crude odds ratios (COR) and their $95 \%$ confidence intervals (CI) were calculated. Significant factors using stepwise forward Wald method to detect the independent predictor of acceptance. AOR and their 95\% CI were calculated. $\mathrm{P} \leq 0.05$ was considered statistically significant. 


\section{Results}

Table 1: Nurses' Acceptance of COVID-19 vaccines and its variation with different parameters.

\begin{tabular}{|c|c|c|c|c|}
\hline Parameters & Total & Acceptance & p value & COR $(95 \% \mathrm{CI})$ \\
\hline Overall & 262 & $58(22.1)^{\mathrm{a}}$ & & \\
\hline $\begin{array}{l}\text { Age (years): } \\
<30 \\
\geq 30\end{array}$ & $\begin{array}{l}107 \\
155\end{array}$ & $\begin{array}{l}19(17.8) \\
39(25.2)\end{array}$ & 0.2 & $\begin{array}{c}1(\mathrm{r}) \\
1.6(0.8-2.9)\end{array}$ \\
\hline $\begin{array}{l}\text { Sex: } \\
\text { Female } \\
\text { Male } \\
\end{array}$ & $\begin{array}{c}217 \\
45\end{array}$ & $\begin{array}{l}42(19.4) \\
16(35.6)\end{array}$ & 0.02 & $\begin{array}{c}1(r) \\
2.3(1.1-4.6)\end{array}$ \\
\hline $\begin{array}{l}\text { Residence: } \\
\text { Urban } \\
\text { Rural } \\
\end{array}$ & $\begin{array}{c}77 \\
185 \\
\end{array}$ & $\begin{array}{l}20(26.0) \\
38(20.5) \\
\end{array}$ & 0.3 & $\begin{array}{c}1(\mathrm{r}) \\
0.7(0.4-1.4)\end{array}$ \\
\hline $\begin{array}{l}\text { Marital status: } \\
\text { Unmarried } \\
\text { Married } \\
\end{array}$ & $\begin{array}{c}63 \\
199 \\
\end{array}$ & $\begin{array}{l}11(17.5) \\
47(23.5) \\
\end{array}$ & 0.3 & $\begin{array}{c}1(\mathrm{r}) \\
1.5(0.7-3.0)\end{array}$ \\
\hline $\begin{array}{l}\text { Income: } \\
\text { Insufficient } \\
\text { Sufficient }\end{array}$ & $\begin{array}{c}173 \\
89 \\
\end{array}$ & $\begin{array}{l}38(22.0) \\
20(22.5)\end{array}$ & 0.9 & $\begin{array}{c}1(\mathrm{r}) \\
1.0(0.7-3.0)\end{array}$ \\
\hline $\begin{array}{l}\text { Department: } \\
\text { Medical } \\
\text { Surgical } \\
\text { Others } \\
\end{array}$ & $\begin{array}{c}43 \\
57 \\
162 \\
\end{array}$ & $\begin{array}{c}11(25.6) \\
9(15.8) \\
38(23.5) \\
\end{array}$ & $\begin{array}{l}0.2 \\
0.8 \\
\end{array}$ & $\begin{array}{c}1(\mathrm{r}) \\
0.5(0.2-1.5) \\
0.9(0.4-1.9) \\
\end{array}$ \\
\hline $\begin{array}{l}\text { Duration of work (years): } \\
<10 \\
\geq 10 \\
\end{array}$ & $\begin{array}{l}132 \\
130 \\
\end{array}$ & $\begin{array}{l}26(19.7) \\
32(24.6) \\
\end{array}$ & 0.3 & $\begin{array}{c}1(\mathrm{r}) \\
1.3(0.7-2.4) \\
\end{array}$ \\
\hline $\begin{array}{l}\text { Scientific qualification: } \\
\text { Nursing Diploma } \\
\text { Bachelor of nursing }\end{array}$ & $\begin{array}{c}169 \\
93\end{array}$ & $\begin{array}{l}35(20.7) \\
23(24.7)\end{array}$ & 0.5 & $\begin{array}{c}1(\mathrm{r}) \\
1.3(0.7-2.3)\end{array}$ \\
\hline $\begin{array}{l}\text { Training on COVID-19: } \\
\text { Yes } \\
\text { NO }\end{array}$ & $\begin{array}{c}178 \\
84\end{array}$ & $\begin{array}{l}43(24.2) \\
15(17.9)\end{array}$ & 0.3 & $\begin{array}{c}1(\mathrm{r}) \\
0.7(0.4-1.3)\end{array}$ \\
\hline $\begin{array}{l}\text { Infection expectation: } \\
\text { NO Mild/ } \\
\text { Moderate } \\
\text { Severe } \\
\text { Already infected }\end{array}$ & $\begin{array}{c}55 \\
60 \\
42 \\
105\end{array}$ & $\begin{array}{c}7(12.7) \\
12(20.0) \\
9(21.4) \\
30(28.6)\end{array}$ & $\begin{array}{c}0.3 \\
0.3 \\
0.02\end{array}$ & $\begin{array}{c}1(\mathrm{r}) \\
1.7(0.6-4.7) \\
1.9(0.6-5.5) \\
2.7(1.1-6.7)\end{array}$ \\
\hline $\begin{array}{l}\text { Self-rated health status: } \\
\text { Poor } \\
\text { Good/fair }\end{array}$ & $\begin{array}{c}73 \\
189\end{array}$ & $\begin{array}{c}7(9.6) \\
51(27.0)\end{array}$ & 0.002 & $\begin{array}{c}1(\mathrm{r}) \\
3.5(1.5-8.1)\end{array}$ \\
\hline
\end{tabular}

a $: 4.2 \%$ already vaccinated and $17.9 \%$ are willing to take the vaccine. CI=confidence interval. $\mathrm{COR}=$ Crude odds ratio. $\mathrm{r}=$ reference category. 
Table 1 showed sociodemographic, work related, and other determinants of nurses' acceptance to COVID-19 vaccines. A total of $22.1 \%$ of study participants accepted vaccines $(4.2 \%$ already vaccinated and $17.9 \%$ are willing to take the vaccine). Being a male, previously infected, with good or fair self-rated health were associated with more vaccine acceptance with COR, 2.3, 2.7 and 3.5; respectively.

Table 2: Multivariate logistic regression analysis of independent predictor of vaccine acceptance.

\begin{tabular}{|l|c|c|c|}
\hline \multicolumn{1}{|c|}{ Predictors } & $\boldsymbol{\beta}$ & $\mathbf{p}$ value & AOR (95\% CI) \\
\hline $\begin{array}{l}\text { Self-rated health status: } \\
\text { Poor Good/fair }\end{array}$ & 1.25 & $\mathbf{0 . 0 0 4}$ & $1(\mathrm{r})$ \\
\hline $\begin{array}{l}\text { Constant } \\
\text { Model c } c^{2} \\
\text { Correctly predicted }\end{array}$ & $\begin{array}{l}-2.2 \\
\text { Co.5 (p } \mathbf{0 0 . 0 0 1}) \\
77.9\end{array}$ & & \\
\hline
\end{tabular}

$\mathrm{AOR}=$ Adjusted odds ratio.

$\mathrm{CI}=$ confidence interval.

$\mathrm{r}=$ reference category.

Table 2 showed that the independent predictor on logistic regression is good/ fair self-rated health with $\mathrm{AOR}=3.5$ (1.5-8.1). This can predict $77.9 \%$ of vaccine acceptance.

Table 3: Reasons for not accepting vaccines (204 nurses are not accepting the vaccines).

\begin{tabular}{|l|c|}
\hline Reasons $^{\text {a }}$ & No (\%) \\
\hline Safety issues/ concerns about side effects & $153(75.0)$ \\
\hline Efficacy issues & $151(74.0)$ \\
\hline Distrust in vaccine manufacturing companies, or the vaccine itself & $123(60.3)$ \\
\hline Lack of information regarding COVID-19 vaccine & $87(42.6)$ \\
\hline Recommendation from health care worker due to incompatibility to health & $49(24.0)$ \\
\hline Bad previous experience with influenza vaccines & $26(12.7)$ \\
\hline Presuming that it is too early to be vaccinated & $15(7.4)$ \\
\hline Dislike injections & $15(7.4)$ \\
\hline Assuming self to be not at risk & $12(5.9)$ \\
\hline
\end{tabular}

${ }^{a}:$ Categories are not mutually exclusive.

Table 3 showed that the most common causes of not accepting vaccines are safety issues and side effects considerations. This is followed by trust issues related to current COVID-19 vaccines manufacture, and lack of information. 


\section{Discussion}

Nurses are largely exposed to COVID-19 infection. Their vaccination is considered a crucial preventive strategy. Till now, there are still some issues around COVID-19 vaccines' acceptance among nurses. This needed to be investigated. The current study found that only $22.1 \%$ of nurses in Mansoura University Hospitals, Egypt, accept COVID-19 vaccines (Table 1). A systematic review stated that COVID-19 vaccine acceptance rates among doctors and nurses varied from as low as $27.7 \%$ in Congo to as high as $78.1 \%$ in Israel (Sallam, 2021). Another research work that included 35 studies with sample sizes ranging from 123 to 16,158 reported that vaccine hesitancy among health care workers including nurses ranged from $4.3 \%$ to $72 \%$ (Biswas et al., 2021). A cross sectional survey concluded that $40 \%$ of nurses in China accepted COVID-19 vaccination (Wang et al., 2020). According to the present study, $4.2 \%$ were already vaccinated at the time of data collection (Table 1). This is considered by far very low in terms of vaccine coverage. Vaccine is freely available in Mansoura University Hospitals and health care workers including nurses are given top priority to get the vaccine. A previous study stated that COVID-19 vaccine coverage among nursing staff reached $37.5 \%$ in the United States (Gharpure et al., 2021).

The present work stated that $17.9 \%$ of nurses were willing to be vaccinated (Table 1). This is also considered low compared to other studies that estimated hypothetical vaccine acceptance to be $76.9 \%$ among French healthcare workers during the first pandemic wave (Gagneux-Brunon et al., 2021). This could be low awareness about importance and safety of the vaccine.

Good self-rated general health was detected to be an independent predictor in among the studied group. AOR (95\%) CI was 3.5 (1.5-8.1) (Table 2). This could be partially explained by the Health Belief Model (HMB). It has four components; 1 . Perceived susceptibility, which is expected to be low in those with good self-rated general health. 2 . Perceived severity, which may be high due to presumed increased concerns about health. 3. Perceived barriers which are low due to vaccine availability. 4 . Perceived benefits of vaccination which are expected to be high among with good health status. The overall sum of health belief model in those with high 
self-rated general health is in the favour of getting vaccinated (Zampetakis and Melas, 2021). Another explanation might be the association between good general health and awareness about healthy habits including specific prevention of diseases by vaccination (Banik et al., 2021). This agreed with a study done in United States which stated that among health care workers with no chronic medical conditions and average general health, $7.4 \%$ refused vaccine, $36 \%$ accepted, and $57 \%$ did not give a conclusive answer (Shekhar et al., 2021).

According to the present study, male nurses and those who are previously infected were more likely to accept COVID-19 vaccination (Table 1). This was in accordance with a systematic review done in United States, which stated that doctoral degree holders and older male health care workers were more likely to accept the vaccine than others (Biswas et al., 2021). Also, it was in harmony with a study done by Qattan et al., 2021 on acceptability of COVID-19 vaccine among healthcare workers in the Kingdom of Saudi Arabia who documented that being a male and at higher infection risk perception was more likely to be associated with vaccine acceptance. Male sex is reported to be positively associated with vaccine acceptance among health care workers (Dror et al., 2020). It is possible that being a male might be associated to holding positions with more exposure to infection, and that females may have more safety concerns given the fact that most female nurses working in Mansoura University Hospitals are in the reproductive age and assigned duties not in direct contact with COVID-19 patients.

A research work done on health care workers whose participants were more than $60 \%$ nurses, reported that being infected during COVID-19 pandemic was associated with more psychological impacts including generalized anxiety disorders (Temsah et al., 2020). From authors' perspective, this explains more willingness to be vaccinated among previously infected nurses.

The current study revealed that among the reasons for not accepting the vaccine, concerns about vaccine side effects were ranked the highest (75\%), followed by assuming ineffectiveness of the vaccines (74\%), followed by distrust in vaccine producing companies or the vaccine itself $(60.3 \%)$ (Table3). Uncertainties that 
may surround vaccine efficacy, safety issues, strict time schedules, in addition to believing sometimes that it might not be necessary were reported by some studies as reasons for vaccine hesitancy among health care workers (Wang et al., 2020). A national survey performed on 1000 people in United States reported that, regarding COVID-19 vaccines' acceptance, people evaluate benefits and side effects independently (Kaplan and Milstein, 2021). Some studies addressed insufficient health care workers' knowledge about the vaccine as the most important factor for vaccine hesitancy (Papagiannis et al., 2020). Dror et al., 2020 in their study on vaccine hesitancy: the next challenge in the fight against COVID-19 concluded that nurses believed that COVID-19 is a mild illness in comparison to issues about safety and effectiveness of the vaccine which was documented as a limiting factor against increasing COVID-19 vaccination coverage among hospitals staff. Uncertainties about the duration of protection provided by COVID-19 vaccine were added to safety and efficacy concerns and documented as reasons for vaccine hesitancy among nurses (Kwok et al., 2021).
Some studies hypothesized new reasons such as negative effects of social media in misinforming health care workers in addition to rumours on vaccine quality (Nzaji et al., 2020). Authors believe that under regular conditions, social media should have a minimal role in forming the knowledge of professional people such as health care workers, but under the global stress from the pandemic, these hypotheses might be a possibility. Some studies addressed distrust in pharmaceutical companies in addition to safety and efficacy concerns as disabling factors against vaccine acceptability among health care workers (Di Gennaro et al., 2021). Many other research work addressed COVID-19 vaccine safety and effectiveness as major limiting factors for vaccine acceptability by health care workers (Eguia et al., 2021; Kuter et al., 2021; Ledda et al., 2021; Shekhar et al., 2021). A national Egyptian survey on COVID-19 vaccine acceptability among health care workers reported that $13.5 \%$ accepted the vaccine and that concerns about safety and efficacy were significant limiting factors against high vaccination (Mohamed-Hussein et al., 2021).

Conclusion: COVID-19 vaccines 
acceptability among nurses in Mansoura University Hospitals is relatively low for a high-risk population. Most of the attributed reasons can be managed by health education campaigns.

\section{Recommendations: Education} is of crucial importance in the overall process of protection of nurses against COVID-19 infection. Education should target the most relevant issues to increase nurses' awareness for prevention of occupational and community-acquired COVID-19 infections.

Study limitations: The current study has some limitations; being a self-reported cross section survey, that was conducted in a single centre. Some types of bias can be present such as Neyman's and recall bias.

\section{Conflict of interest}

Authors declare that there is no conflict of interest.

\section{Data availability statement}

Data are available upon reasonable request from the corresponding author.

\section{Funding}

This research work is self-funded.

\section{Acknowledgment}

Authors thank every nurse who participated in the current study and contributed to the overall conduction of the research work.

\section{References}

1. Abdelhafiz AS, Mohammed Z, Ibrahim ME, Ziady HH, Alorabi M, et al. (2020): Knowledge, Perceptions, And Attitude of Egyptians Towards the Novel Coronavirus Disease (COVID-19). J Com Health; 1-10.

2. Banik R, Islam M, Pranta MUR, Rahman QM, Rahman M, et al. (2021): Understanding the determinants of COVID-19 vaccination intention and willingness to pay: findings from a population-based survey in Bangladesh. BMC Infect Dis; 21(1): 1-15.

3. Biswas N, Mustapha T, Khubchandani $\mathrm{J}$ and Price JH (2021): The Nature and Extent of COVID-19 Vaccination Hesitancy in Healthcare Workers. J Com Health; 1-8. DOI: 10.1007/ s10900-021-00984-3.

4. Di Gennaro F, Murri R, Segala FV, Cerruti L, Abdulle A, et al. (2021): Attitudes Towards AntiSARS-Cov2 Vaccination Among Healthcare Workers: Results from A National Survey in Italy. Viruses; 13(3):371.

5. Dror AA, Eisenbach N, Taiber S, Morozov NG, Mizrachi M, et al. (2020): Vaccine Hesitancy: The Next Challenge in The Fight Against COVID-19. Eur J Epidemiol; 35(8):775-9.

6. Eguia H, Vinciarelli F, Bosque-Prous M, Kristensen T and Saigí-Rubió F (2021): Spain's Hesitation at the Gates of a COVID-19 Vaccine. Vaccines; 9(2):170.

7. Fisher KA, Bloomstone SJ, Walder J, Crawford S, Fouayzi H, et al. (2020): Attitudes Toward a Potential SARS-Cov-2 Vaccine: A Survey of US Adults. Ann Intern Med; 173(12):964-73.

8. Gagneux-Brunon A, Detoc M, Bruel S, Tardy B, Rozaire O, et al. (2021): Intention to Get Vaccinations Against COVID-19 in French Healthcare Workers During the First Pandemic 
Wave: A Cross-Sectional Survey. J Hosp Infect; 108:168-73.

9. Gharpure R, Guo A, Bishnoi CK, Patel U, Gifford D, et al. (2021): Early COVID-19 FirstDose Vaccination Coverage Among Residents and Staff Members of Skilled Nursing Facilities Participating in The Pharmacy Partnership for Long-Term Care Program, United States, December 2020-January 2021. Morb Mort Weekly Rep; 70(5):178.

10. Kaplan RM and Milstein A (2021): Influence of a COVID-19 vaccine's effectiveness and safety profile on vaccination acceptance. Proc Natl Acad Sci; 118(10) e2021726118. https://doi. org/10.1073/pnas.2021726118.

11. Kuter BJ, Browne S, Momplaisir FM, Feemster KA, Shen AK, et al. (2021): Perspectives on the Receipt of A COVID-19 Vaccine: A Survey of Employees in Two Large Hospitals in Philadelphia. Vaccine; 39(12):1693-700.

12. Kwok KO, Li KK, Wei WI, Tang A, Wong SY, et al. (2021): Influenza Vaccine Uptake, COVID-19 Vaccination Intention and Vaccine Hesitancy Among Nurses: A Survey. Int J Nurs Stud; 114:103854.

13. Ledda C, Costantino C, Cuccia M, Maltezou HC, and Rapisarda V (2021): Attitudes of Healthcare Personnel Towards Vaccinations Before and During The COVID-19 Pandemic. Intern J Environ Res Pub Health; 18(5):2703.

14. McIntosh K, Hirsch M, and Bloom A (2020): Coronavirus Disease 2019 (COVID-19): Epidemiology, Virology, and Prevention. Lancet Infect Dis; 1:2019-20.

15. Mohamed-Hussein AA, Makhlouf H, Abd El Aal H, Kholief K, Saad MM, et al. (2021): A National Survey of Potential Acceptance Of COVID-19 Vaccines in Healthcare Workers in Egypt. Available at: https://www.medrxiv.org/co ntent/10.1101/2021.01.11.21249324v1

16. Nicola M, Alsafi Z, Sohrabi C, Kerwan A, AlJabir A, et al. (2020): The Socio-Economic Implications of The Coronavirus And COVID-19 Pandemic: A Review. Intern J Surg;
78:185-93.

17. Nzaji MK, Ngombe LK, Mwamba GN, Ndala DBB, Miema JM, et al. (2020): Acceptability of Vaccination Against COVID-19 Among Healthcare Workers in The Democratic Republic of The Congo. Pragm Observ Res; 11: 103.

18. Papagiannis D, Malli F, Raptis DG, Papathanasiou IV, Fradelos EC, et al. (2020): Assessment of Knowledge, Attitudes, And Practices Towards New Coronavirus (SARSCov-2) Of Health Care Professionals in Greece Before the Outbreak Period. Intern J Environ Res Pub Health; 17(14):4925.

19. Phua J, Weng L, Ling L, Egi M, Lim CM, et al. (2020): Intensive Care Management of Coronavirus Disease 2019 (COVID-19): Challenges and Recommendations. The Lancet Resp Med; 8(5): 506-17.

20. Qattan A, Alshareef N, Alsharqi O, Al Rahahleh N, Chirwa GC, et al. (2021): Acceptability of A COVID-19 Vaccine Among Healthcare Workers in The Kingdom of Saudi Arabia. Front Med; 8: 83.

21. Sallam M (2021): COVID-19 Vaccine Hesitancy Worldwide: A Concise Systematic Review of Vaccine Acceptance Rates. Vaccines; 9(2):160.

22. Shekhar R, Sheikh AB, Upadhyay S, Singh M, Kottewar S, et al. (2021): COVID-19 Vaccine Acceptance Among Health Care Workers in The United States. Vaccines; 9(2): 119.

23. Temsah MH,Al-Sohime F, Alamro N, Al-Eyadhy A, Al-Hasan K, et al. (2020): The Psychological Impact Of COVID-19 Pandemic on Health Care Workers in A MERS-Cov Endemic Country. J Infect Pub Health; 13(6):877-82.

24. Wang J, Peng $\mathrm{Y}, \mathrm{Xu} \mathrm{H}$, Cui $\mathrm{Z}$, and Williams RO (2020): The COVID-19 Vaccine Race: Challenges and Opportunities in Vaccine Formulation. AAPS Pharm Sci Tech; 21(6):112.

25. Wang K, Wong ELY, Ho KF, Cheung AWL, Chan EYY, et al. (2020): Intention of Nurses to Accept Coronavirus Disease 2019 Vaccination and Change of Intention to Accept Seasonal 
Influenza Vaccination During the Coronavirus Disease 2019 Pandemic: A Cross-Sectional Survey. Vaccine; 38(45):7049-56.

26. Wu HH, Chen YT, Shih CJ, Lee YT, Kuo SC, et al. (2014): Association Between Recent Use of Proton Pump Inhibitors and Nontyphoid
Salmonellosis: A Nested Case-Control Study. Clin Infect Dis; 59(11):1554-8.

27. Zampetakis LA and Melas C (2021): The health belief model predicts vaccination intentions against COVID19: A survey experiment approach. Appl Psychol; 13(2): 469-84. 